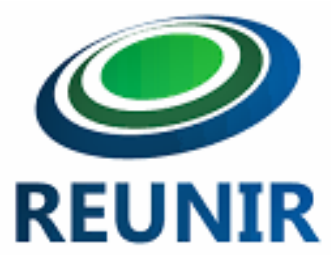

REUNIR:

Revista de Administração, Ciências Contábeis e Sustentabilidade

www.reunir.revistas.ufcg.edu.br

ARTIGO ORIGINAL

\title{
O que você faz com o seu tempo? Um estudo sobre Work-Life-Balance ${ }^{1}$ What do you do with your time? A Work-Life Balance study ¿Qué haces con su tiempo? Un estudio sobre Work-Life Balance
}

\author{
Lucas de Andrade ${ }^{2}$, Joice Denise Schafer ${ }^{3}$, Rogério João Lunkes ${ }^{4}$
}

\section{PALAVRAS-CHAVE Work-Life Balance; Flexibilização da jornada de trabalho; Gestão de tempo.}

\section{KEYWORDS}

Work-Life Balance; Flexible working hours; Time management.

\begin{abstract}
Resumo:
A presente pesquisa se propôs a ampliar os estudos acerca da temática Work-Life Balance. Para tanto, buscou verificar se as características dos funcionários e a flexibilidade da jornada de trabalho proposta por uma empresa de tecnologia da Grande Florianópolis refletem na percepção de gestão adequada de tempo e, respectivamente, no equilíbrio entre vida pessoal e laboral (Work-Life Balance) dos colaboradores. A metodologia utilizada caracteriza-se quanto ao objetivo como descritiva, sendo a coleta de dados realizada com a aplicação de um questionário, por meio da plataforma virtual do "Google Forms". Os dados, advindos do retorno de 38 questionários, foram analisados inicialmente de forma descritiva, o que permitiu identificar um perfil jovem e sem filho dos funcionários, e a percepção dos mesmos sobre a gestão adequada do tempo e de equilíbrio entre vida pessoal e laboral. Com base no Teste $U$ de Mann-Whitney, evidenciou-se que, a diferença da área de formação e idade foram estatisticamente significativas no que se refere ao tempo de sono (variável da gestão de tempo), assim como a formação parece influenciar o equilíbrio entre vida pessoal e laboral (para a variável redução de carga horária com redução proporcional de salário). A flexibilização da carga horária de trabalho por parte da empresa não parece exercer influência sobre a percepção dos funcionários quanto a gestão de tempo e equilíbrio da vida pessoal e laboral. Este resultado pode ser justificado pela política de promoção de um ambiente de trabalho descontraído por parte da empresa a todos os funcionários.
\end{abstract}

\footnotetext{
1 Submetido em 06.10.2017. Publicado em 20.07.2019. Responsável Universidade Federal de Campina Grande/UACC/PROFIAP/CCJS/UFCG.

2 Graduado em Ciências Contábeis. Universidade Federal de Santa Catarina. Email: lucas@skep.education, ORCID: https://orcid.org/0000-0002-2860-7635

3 Doutoranda em Contabilidade, Universidade Federal de Santa Catarina. E-mail: schafer.joice@gmail.com, ORCID: https://orcid.org/0000-0001-6779-1079

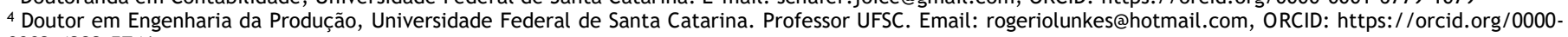
$0003-4232-5746$
} 
PALABRAS CLAVE Work-Life Balance; Flexibilización de la jornada de trabajo; Gestión de tiempo
"Google Forms" virtual platform. The data, which resulted from the return of 38 questionnaires, were initially analyzed in a descriptive way, which allowed the identification of a young and childless profile of the employees, and their perception about the adequate management of time and the balance between personal and work life. Based on the Mann-Whitney $U$ test, it was shown that the difference in training area and age were statistically significant with regard to sleep time (time management variable), as well as training seems to influence the balance between personal and work life (for the variable reduction of workload with proportional reduction of salary). The flexibilization of the working hours by the company does not seem to exert influence on the perception of the employees regarding the management of time and balance of personal and labor life. This result can be justified by the policy of promoting a relaxed working environment on the part of the company to all employees.

\section{Resumen:}

La presente investigación se propuso ampliar los estudios acerca de la temática Work-Life Balance. Para ello, buscó verificar si las características de los empleados y la flexibilidad de la jornada de trabajo propuesta por una empresa de tecnología de la Grande Florianópolis reflejan en la percepción de gestión adecuada de tiempo y, respectivamente, en el equilibrio entre vida personal y laboral (Work-Life Balance de los colaboradores. La metodología utilizada se caracteriza en cuanto al objetivo como descriptiva, siendo la recolección de datos realizada con la aplicación de un cuestionario, a través de la plataforma virtual del "Google Forms". Los datos, provenientes del retorno de 38 cuestionarios, fueron analizados inicialmente de forma descriptiva, lo que permitió identificar un perfil joven y sin hijo de los funcionarios, y la percepción de los mismos sobre la gestión adecuada del tiempo y de equilibrio entre vida personal y laboral. En base a la prueba U de Mann-Whitney, se evidenció que la diferencia en el área de formación y edad fue estadísticamente significativa en lo que se refiere al tiempo de sueño (variable de la gestión del tiempo), así como la formación parece influenciar el equilibrio entre vida personal y laboral (para la variable reducción de carga horaria con reducción proporcional de salario). La flexibilización de la carga horaria de trabajo por parte de la empresa no parece ejercer influencia sobre la percepción de los funcionarios en cuanto a la gestión de tiempo y equilibrio de la vida personal y laboral. Este resultado puede estar justificado por la política de promoción de un ambiente de trabajo relajado por parte de la empresa a todos los empleados. 


\section{Introdução}

O Work-Life Balance é uma temática atual que está relacionada com o tempo que os indivíduos destinam ao trabalho e a vida pessoal. Moen, Kelly, Tranby and Huang (2011a) argumentam que o elemento tempo, especialmente o tempo no trabalho, é um dos maiores modeladores das atividades humanas, incluindo as consequências relacionadas à saúde. De acordo com Covey (1989), quatro ondas ou gerações de administração do tempo podem ser identificadas.

A primeira onda caracterizou-se pelo uso de bilhetes e listas, com o propósito de exprimir uma aparência de organização, em função das demandas feitas sobre o tempo e energia disponíveis. A segunda, se baseou em calendários e agendas, conferindo uma onda que reflete a tentativa de olhar para a frente, para o futuro. A terceira abordou conceitos de metas e prioridades e apesar de ter contribuições significativas com a proposta da elaboração de agendas "eficazes" e controle do tempo, notou-se que muitas vezes são improdutivas, pois "a concentração na eficácia gera expectativas que conflitam com as oportunidades de desenvolver relacionamentos mais ricos, de satisfazer as necessidades humanas, e de desfrutar momentos espontâneos diariamente" (Covey, 1989, p. 97). A quarta geração, atualmente emergente, diferencia-se das demais, uma vez que entende que o desafio não é administrar o tempo, mas as pessoas. Esta onda tem o seu foco na preservação e melhoria dos relacionamentos, nos papéis de cada indivíduo, e na obtenção de resultados.

Segundo Andrade (2011), essa nova configuração remonta aos anos 1960, mais precisamente nos Estados Unidos, com a crescente inserção da mulher nas carreiras profissionais e mudanças no cenário econômico-social, que antes apontava a figura masculina como responsável pelo rendimento familiar, enquanto a mulher realizaria tarefas mais voltadas para a manutenção da família e do lar. A inserção das mulheres no mercado de trabalho, conforme o autor, também teria levado os cientistas sociais a se preocuparem mais com as possíveis consequências relacionadas ao equilíbrio da vida profissional e da organização da vida familiar.

Em seus estudos, Altoé (2014) destaca o desencadeamento do conflito dos papéis assumidos pelos indivíduos, ressaltando que os mesmos, além de funcionários de uma organização, que almejam destaque profissional, são pais, cônjuges, desempenham atividades domésticas, entre outros. Diante dessa situação, "com o propósito de reduzir os conflitos de papéis e contribuir para o bem-estar das pessoas", a questão do Work-Life Balance passou a ser discutida (Altoé, 2014, p. 109).

O surgimento dos estudos, a partir dos anos 1960, das relações conflituosas entre o trabalho e a vida pessoal dos trabalhadores, ou do Work-Life Balance, são indícios da responsabilidade crescente e competitiva entre essas duas esferas, além de ser considerado um dos maiores desafios da sociedade moderna, se tornando um dos principais assuntos da agenda da Comissão Europeia. Essa agenda traz orientações de melhorias nas práticas organizacionais com o intuito de possibilitar, tanto a satisfação laboral, quanto a pessoal dos trabalhadores (Andrade, 2011). Estas práticas incluem, por exemplo, a flexibilização da jornada de trabalho, que permite aos trabalhadores variariarem seus horários de entrada e saída do emprego, desde que um determinado número de horas seja trabalhado, ou comprimir a semana de labor, trabalhando a quantidade de horas de uma semana inteira em quatro dias, sendo o quinto de folga (Beauregard and Henry, 2009).

A utilização de tais práticas, como a flexibilização de horários trabalho, que visam a melhoria do equilíbrio entre vida pessoal e profissional, no entanto, devem ser planejadas cuidadosamente, tendo em vista que resultados divergentes foram encontrados em estudos sobre sua utilização (Saltzstein, Ting, \& Saltzstein, 2001; Baltes, Clark, \& Chakrabarti, 2010). Em alguns casos a oferta de flexibilização acaba incentivando os funcionários a trabalharem ainda mais do que na rotina tradicional de horários (Suttton \& Noe, 2005).

Diante das contradições existentes na literatura sobre a contribuição efetiva da flexibilização da jornada de trabalho para o Work-Life Balance, as diferentes ações dos indivíduos diante dessa possibilidade, e o crescente interesse sobre a temática a partir do final da década de 1990, bem como a conscientização emergente das organizações que tem buscado práticas que proporcionam um maior equilíbrio entre a vida laboral e pessoal de seus colaboradores, este trabalho tem como objetivo verificar se as características dos funcionários e a flexibilidade da jornada de trabalho proposta por uma empresa de tecnologia da Grande Florianópolis refletem na percepção de gestão adequada de tempo e, respectivamente, no equilíbrio entre vida pessoal e laboral (Work-Life Balance) dos colaboradores.

A presente pesquisa busca ampliar o debate sobre políticas das empresas que podem levar os profissionais a sentirem-se satisfeitos, ao mesmo tempo, com a vida profissional e pessoal, levando o trabalhador a ter melhor qualidade de vida e sentir se motivado ao longo das rotinas profissionais. Este estudo afasta-se, portanto, da visão de remuneração econômica tradicional, e centra as discussões na importância da gestão do tempo e equilíbrio entre a vida profissional e pessoal dos trabalhadores.

\section{Revisão da literatura e desenvolvimento de hipóteses}

O uso de uma abordagem que visa o equilíbrio entre trabalho e vida pessoal para gerar o bem-estar dos funcionários emergiu como uma ferramenta estratégica de gerenciamento de recursos humanos (método ou questão) no mundo ocidental (Wong \& Ko, 2009). As demandas concorrentes entre trabalho e casa assumiram uma relevância crescente para os empregados nos últimos anos, em grande parte devido a mudanças demográficas e no local de trabalho, como: o aumento do número de mulheres na força de trabalho, o envelhecimento da população e as tecnologias de comunicação, que se tornaram mais sofisticadas, permitindo o contato quase constante dos trabalhadores com o local de trabalho (Beauregard \& Henry, 2009). 
Ao mesmo tempo que, para a maioria das pessoas, o trabalho garante uma vida melhor e proporciona o bemestar da família, a sobrecarga laboral pode levar a um conflito de papeis (Chandra, 2012). O Work-Life Balance relaciona-se, justamente, com o desencadeamento do conflito dos papéis de trabalho dos indivíduos que, segundo Baltes et al. (2010), ocorrem quando o indivíduo percebe que a demanda desses papéis excede os seus recursos, como o tempo. Por outro lado, quando os trabalhadores percebem que os papeis atribuídos respeitam ou complementam seus papéis na vida pessoal e laboral, são vistos como facilitadores. Neste sentido, a pesquisa desenvolvida por Isaacs (2016, p. 168) em Massachusetts, na instituição Framingham Heart Study, apontou que "a pessoa que se sente no controle do seu trabalho é susceptível a se sentir no controle da sua vida e do seu equilíbrio entre a vida laboral e pessoal" (Isaacs, 2016, p. 168).

Iniciativas das organizações destinadas a satisfazer o "Work-Life Balance" dos colaboradores são indicadas por Baltes et al. (2010), dentre elas, destacam-se: semanas de trabalho comprimidas, trabalhos "online" à distância, creches para crianças no local de trabalho e, a flexibilização da carga horária - a mais praticada dentre elas -, a qual, segundo os autores, é mais comumente oferecida em empresas de pequeno porte, tendo um crescimento na sua implementação desde 1998. De acordo com Baltes et al. (2010), a flexibilização da carga horária estaria significativamente relacionada ao crescimento da produtividade, à satisfação com o trabalho e seus horários, ao absentismo, à lealdade do empregado e até mesmo à redução dos conflitos entre a vida laboral e familiar e, consequentemente, ao seu equilíbrio.

Os resultados da pesquisa de Baltes et al. (2010), no entanto, não podem ser generalizados, pois há indícios de que nem todas as experiências de flexibilização organizacional obtiveram sucesso. Um estudo desenvolvido nos Estados Unidos, por exemplo, desenvolvido por Saltzstein et al. (2001) com mais de trinta mil funcionários do governo não conseguiu relacionar a flexibilização da carga horária com a satisfação do equilíbrio da vida pessoal e profissional dos mesmos. Estes achados podem ser justificados pelas informações obtidas na pesquisa de Suttton e Noe (2005) que identificaram que as organizações não oferecem grande flexibilização e, quando oferecem, o número de horas de trabalho tende a aumentar, pois quando as pessoas possuem autonomia para administrá-lo, muitas vezes acabam trabalhando um tempo maior. Desta forma, os trabalhadores acabam comprometendo uma parte ainda maior de seu tempo e energia com o trabalho, consequentemente levando a um desequilíbrio entre este e a vida pessoal (Baltes et al., 2010).

Cabe destacar, ainda, que existem outros fatores considerados “ladrões de tempo" (fatores responsáveis pela perda da produtividade) como a procrastinação, navegações na internet sem importância e falta de planejamento de gestão do tempo (Lima \& Jesus, 2012), que podem levar o indivíduo a ter que dedicar maior parcela de seu tempo e energia a atividades laborais. Neste contexto, as ferramentas de gestão de tempo se distinguem da autonomia de controlar os horários de trabalho e torna-se possível relacioná-los. Caso os fatores responsáveis pela perda da produtividade mencionados levem o trabalhador a dedicar um tempo maior para concluir suas atividades profissionais, por exemplo, as ferramentas de gestão de tempo apresentam-se como auxiliadoras, enquanto a autonomia para controlar os horários, como metodologia, gera dúvidas quanto à efetividade no equilíbrio entre a vida pessoal e laboral. Neste sentido, Altoé (2016) desenvolveu uma pesquisa com 267 contadores paranaenses, com o objetivo de identificar os fatores que explicam a percepção dos mesmos quanto ao seu Work-Life Balance e verificar a relação destes fatores com a gestão do tempo. Os resultados indicaram que os contadores que apresentam uma jornada excessiva de trabalho acreditam que esta dedicação reflete negativamente nas demais esferas e consequentemente impacta na sua percepção de Work-Life Balance.

Embora as pessoas, no geral, procurarem o equilíbrio entre vida pessoal e profissional, a preocupação com o sucesso da carreira, no entanto, atrai-os para uma situação em que se trabalha cada vez mais, logo, acaba-se experimentando uma insatisfação cada vez maior na relação trabalho-vida pessoal (Chandra, 2012). Assim, a escolha entre um equilíbrio, ou uma maior dedicação ao trabalho, tende a variar entre diferentes pessoas e fases do ciclo de vida. Conforme Chandra (2012), com base nas preferências e circunstâncias individuais, características demográficas, entre outras, as pessoas podem e têm opiniões ou atitudes diferentes em relação às expectativas relacionadas a vida profissional e privada, logo a forma como gerem seu tempo. Tal afirmativa sustenta as primeiras hipóteses desta pesquisa:

H1: Há diferença na percepção da gestão de tempo entre indivíduos com características distintas.

H2: Há diferença na percepção de Work-Life Balance ente indivíduos com características distintas.

No que tange pesquisas internacionais que abordam o Work-Life Balance, relacionando-o com a flexibilização do trabalho, um aspecto comumente abordado é o ROWE implementation, ou seja, a implementação de um ambiente de trabalho com foco em resultados, abordando a relação do autocontrole dos colaboradores com as cargas horárias de trabalho. Baltes et al. (2010), relacionam essa flexibilização com fatores como a chamada gestão estratégica de fronteiras ("boundary management strategy"), que trata das barreiras internas da organização, abordando os conceitos de segmentação e integração no âmbito da gestão estratégica para contextualizar outros fatores que também influenciam no workfamily balance dos colaboradores e, consequentemente, no Work-Life Balance.

De acordo com Moen, Kelly e Hill (2011b), o trabalho contemporâneo evidencia dois aspectos na vida dos trabalhadores: a rotatividade de pessoal (turnovers) com frequência e a pressão decorrente do tempo. Independentemente do seu gênero, idade ou estágio familiar de vida, há indícios de que trabalhadores participando de iniciativas de um ambiente de trabalho com foco em resultado Results Only Work Environment (ROWE) initiatives -, dotadas de autonomia e flexibilidade oferecidas em relação às horas de trabalho, tem menores chances de trocar de emprego. Em outras palavras, a medida ajuda a reduzir os índices de turnovers. 
Dentro da visão de alguns empregadores, as pessoas com altas demandas de tempo em sua vida pessoal não dariam conta da alta demanda de trabalho e esse fator estaria relacionado à falta de gestão dos múltiplos papéis nas suas vidas. Dessa forma, segundo Moen et al. (2011b), a responsabilidade da má administração do Work-Life Balance é transferida para essas pessoas. 0 autor contextualiza, como um exemplo, o caso das gestantes que enfrentam essa situação. De acordo com estudos na universidade de Minnesota, há evidências de que com a flexibilização das jornadas de trabalho, pode-se obter uma redução da alta rotatividade de funcionários por problemas de insatisfação (Moen et al., 2011b).

Moen, Fan e Kelly (2013) observaram, ainda, que iniciativas de flexibilidade de tempo relacionadas aos ROWE promovem impacto na saúde dos trabalhadores, reduzindo o tabagismo e alcoolismo, promovendo percepções de um tempo adequado para refeições saudáveis e para o sono e até mesmo aumentando a frequência da prática de exercícios físicos, ou seja, tendem a proporcionar maior qualidade de vida aos colaboradores da organização. Outra iniciativa praticada, no sentido de flexibilização de jornada de trabalho é o programa Previsibilidade, Montagem de Equipes e Comunicação aberta - Predictability, Teaming and Open Communication (PTO) -, que ao contrário do ROWE, não está relacionada com a flexibilização individualmente, mas coletivamente, dando autonomia para o grupo tomar decisões relacionadas à flexibilização de modo que, ao final, o trabalho esteja igualmente completado (Perlow \& Kelly, 2014). É uma maneira de unir a equipe e darlhes flexibilidade, de forma que, todos trabalhem em prol de suprir a falta de um elemento, sem deixar que isso prejudique os resultados.

A flexibilização de horários recebe influência das presentes transformações da sociedade moderna e é apontada como possibilidade de iniciativa de geração de postos de trabalho sendo uma ferramenta para redução do desemprego na economia atual (Vogelmann, 2012). Cabe destacar, que

O mundo do trabalho está mudando. Está se tornando mais virtual, mais global e mais tecnologicamente avançado. Expectativas de quando $e$ onde o trabalho é feito também estão mudando. Espera-se que, profissionais, gerentes, e muitos funcionários técnicos estejam constantemente conectados em qualquer lugar, a qualquer momento (Perlow \& Kelly, 2014, p. 3).

Diante deste cenário, ideologias distintas quanto à melhor diretriz para o tratamento da flexibilização e seus efeitos são defendidas e, dentro dos estudos de Vignoli (2010) e Tasca e Bezerra (2017), há pelo menos três correntes distintas sobre o tema: a flexibilista, a antiflexibilista e a semiflexibilista, também chamada de intermediária ou mista. A primeira defende a questão protecionista, apontando que a regulamentação governamental com o auxílio dos sindicatos devem ser os agentes responsáveis por solucionar os problemas das relações de trabalho para que tanto as condições do empregador como as do empregado sejam satisfeitas.

A segunda entende que essa flexibilização seria prejudicial aos direitos adquiridos do trabalhador, apoiada por uma ideologia neoliberal que considera que a desproteção ou desregulamentação desses direitos "possibilita um mercado altamente competitivo, ganhando a competição o trabalhador mais eficaz e o empregador mais esperto" (Vignoli, 2010, p. 28). Os estudos de Robortella (1994), por exemplo, apontam que na Europa a flexibilização não resultou em melhorias no desemprego e pode estar associada a diminuição dos padrões salariais.

A terceira, diferentemente das outras, não é radical. Tem a intenção de adequar uma conduta flexível à intervenção do Estado, acreditando que "seria possível garantir aos trabalhadores o não-retrocesso a direitos que lhe são tão caros, bem como apresentar aos empregadores alternativas para a sobrevivência de seus estabelecimentos em situações adversas" (Tasca \& Bezerra, 2017).

Dentro desta mesma abordagem Vignoli (2010) contrapõe dois caminhos distintos: um deles, chamado de irracional, que não respeita a regulamentação dos direitos trabalhistas e o outro, adjetivado como indispensável, pois favorece uma aplicação "prática, fácil e eficiente das normas legais, pela supressão dos requisitos mínimos legais excessivamente minuciosos ou burocráticos, sem que ocorra, entretanto, a mitigação dos direitos indispensáveis do trabalhador" (Vignoli, 2010, p. 89).

No que tange a situação brasileira, no segundo semestre de 2016 a revista Exame apresentou oito exemplos de empresas com diferentes modelos de flexibilização de jornadas de trabalho, sendo que um dos pontos destacados pelas mesmas como dificultador da implementação de tal prática era justamente o fato da legislação trabalhista no Brasil não prever tal condição. Com as mudanças propostas pela reforma trabalhista apresentada em abril deste ano (2017), no entanto, medidas relacionadas à flexibilização da jornada de trabalho passam a ser regulamentadas, facilitando alguns pontos na implementação da flexibilização por parte das empresas.

Diante das mudanças no cenário atual, inclusive no que tange a legislação trabalhista do Brasil, a flexibilização do horário de trabalho passa a ser empregada cada vez mais pelas empresas, o que impacto em maior qualidade de vida dos trabalhadores, uma vez que permite que os mesmos tenham tempo para preparar refeições saudáveis, dormir, praticar exercícios físicos, enfim, tenham uma rotina saudável (Moen et al., 2013) Com isso, espera-se que os funcionários possam gerir o tempo de acordo com suas necessidades e sintam-se melhor para desempenhar suas atividades laborais, reduzindo, assim, a alta rotatividade de funcionários por problemas de insatisfação (Moen et al., 2011b). Assim, a presente pesquisa espera encontrar que:

H3: Há diferença na percepção da gestão de tempo entre indivíduos com carga horária de trabalho flexibilizada e não flexibilizada.

H4: Há diferença na percepção de Work-Life Balance entre indivíduos com carga horária de trabalho flexibilizada e não flexibilizada. 


\section{Elementos metodológicos da pesquisa}

A pesquisa caracteriza-se como descritiva e quantitativa, sendo a coleta de dados realizada por meio da plataforma virtual do "Google Forms". Para o desenvolvimento do estudo apenas uma empresa, que conta com setores com horários de trabalho flexibilizado e outros que possuem horários fixos, foi selecionada. A Involves, fundada em 2008, inserida no segmento de tecnologia e inovação, cresceu até se tornar um modelo Software as a Service (Saas), por meio do desenvolvimento de um produto de grande peso na evolução da organização incorporado à uma plataforma de "trade marketing", o Agile Promoter. Hoje, possui infraestrutura nas cidades de Florianópolis e São Paulo e teve um crescimento de mais de $100 \%$ na evolução patrimonial nos últimos 6 meses, além de ganhar um prêmio de melhor empresa de tecnologia para se trabalhar no Great Place to Work 2016, no Brasil, e no mesmo ano, de melhor empresa para se trabalhar em Santa Catarina.

Atualmente, a empresa conta com mais de 100 funcionários contratados que se subdividem em dez setores identificados na organização, dos quais, segundo a diretoria, seis pertencem ao grupo dos setores com horários totalmente flexíveis - aqui chamados de grupo $\mathrm{A}$ -, enquanto os outros quatro, ao grupo dos com horários não flexibilizados - Grupo B. O Grupo A compreende os setores de: Desenvolvimento Web e Mobile, Infra, Produto, Qualidade, Administrativo e Marketing, diferentemente do Grupo B, que compreende os setores: Sucesso do Cliente, Comercial, Pré-vendas e Suporte e Relacionamento. As duas amostras trabalhadas (flexibilização $x$ não flexibilização de horários), consequentemente, foram identificadas a partir do enquadramento dos integrantes da população nos Grupos A e B. A amostra analisada é composta por 38 respondentes, dos quais 20 correspondem ao grupo $A$ e 18 ao grupo $B$.

Cabe destacar, que existem diversas atividades propostas pela empresa com o objetivo de atender ao Work-Life Balance dos colaboradores como, por exemplo, saídas durante o expediente para a realização de atividades como: boliche, academia, aulas de dança, cinema, rafting, cart, entre outras. Essas medidas são aplicadas em todos os setores, ao contrário das relacionadas à flexibilização dos horários, que são aplicadas distintamente aos grupos A e B.

Os dados dos dois grupos foram coletados por meio de um questionário elaborado e validado no Brasil por Altoé (2014), que desenvolveu um estudo sobre o equilíbrio entre a vida pessoal e profissional com contadores. Este questionário era composto, originalmente, por 22 variáveis explicativas do constructo Work-Life Balance e cinco de gestão de tempo. Por meio de análise fatorial (AF), no entanto, Altoé (2014) identificou que oito questões, relacionadas ao primeiro constructo, deveriam ser excluídas do modelo, isso porque, a exclusão "contribuiu para melhora dos resultados da AF" (Altoé, 2014, p.87), ou seja, as mesmas não se mostraram significativas para 0 modelo. Assim, este estudo tomou como base somente os
14 fatores explicativos (Q1 a Q22) incluídos no modelo de Altoé (2014), que podem ser observados no Quadro 1, juntamente com as variáveis utilizadas para o estudo da gestão de tempo (Q23 a Q27).

A escala utilizada no questionário foi Likert de cinco pontos. Assim, com base nas afirmativas apresentadas no Quadro 1, os funcionários deveriam assinalar 1 para "discordo totalmente", 2 para "discordo parcialmente", 3 para "não concordo nem discordo", 4 para "concordo parcialmente" e 5 para "concordo completamente".

Quadro 1 Variáveis relacionadas ao constructo da pesquisa

\begin{tabular}{|c|c|}
\hline Variáveis explicativas & Referências \\
\hline $\begin{array}{l}\text { Q3 - tenho tempo para a realização de } \\
\text { interesses e aspirações pessoais }\end{array}$ & \multirow{18}{*}{$\begin{array}{l}\text { Clark (2001); } \\
\text { Smith } \\
\text { (2005); } \\
\text { Darcy et al. } \\
\text { (2012); } \\
\text { Wong e Ko } \\
\text { (2009); Wu } \\
\text { et al. } \\
\text { (2013) }\end{array}$} \\
\hline $\begin{array}{l}\text { Q4 - optaria por redução da carga horária } \\
\text { diária de trabalho por um salário } \\
\text { proporcional }\end{array}$ & \\
\hline $\begin{array}{l}\text { Q6 - desistiria de assumir um cargo elevado } \\
\text { no trabalho, para me dedicar mais a família } \\
\text { e vida pessoal }\end{array}$ & \\
\hline $\begin{array}{l}\text { Q7 - meu tempo livre (fora do trabalho) pode } \\
\text { ser utilizado para situações imprevisíveis }\end{array}$ & \\
\hline $\begin{array}{l}\text { Q8 - meus colegas de trabalho compreendem } \\
\text { quando abordo questões pessoais ou } \\
\text { familiares que afetam o trabalho }\end{array}$ & \\
\hline $\begin{array}{l}\text { Q10 - aceito realizar horas extras pois estou } \\
\text { comprometido com o trabalho }\end{array}$ & \\
\hline $\begin{array}{l}\text { Q11 - meu supervisor imediato compreende } \\
\text { quando comento questões pessoais ou } \\
\text { familiares que afetam o trabalho }\end{array}$ & \\
\hline Q12 - levo trabalho para finalizar em casa & \\
\hline $\begin{array}{l}\text { Q13 - aceito realizar horas extras pois é } \\
\text { essencial para a progressão de minha } \\
\text { carreira }\end{array}$ & \\
\hline $\begin{array}{l}\text { Q14 - consigo programar a melhor data para } \\
\text { tirar férias e tenho o apoio de meus colegas } \\
\text { de trabalho }\end{array}$ & \\
\hline $\begin{array}{l}\text { Q15 - consigo conciliar meu trabalho com } \\
\text { minha vida pessoal e familiar, em função da } \\
\text { flexibilidade de horários que o trabalho } \\
\text { proporciona }\end{array}$ & \\
\hline $\begin{array}{l}\text { Q16 - penso em reduzir minha jornada de } \\
\text { trabalho para me dedicar mais tempo as } \\
\text { minhas atividades pessoais ou familiares }\end{array}$ & \\
\hline $\begin{array}{l}\text { Q19 - consigo cumprir com minhas obrigações } \\
\text { no trabalho dentro da carga horária } \\
\text { contratada }\end{array}$ & \\
\hline $\begin{array}{l}\text { Q22 - aceito trabalhar pelo menos } 10 \text { horas } \\
\text { por dia para manter o meu trabalho }\end{array}$ & \\
\hline Q23 - tenho tempo suficiente para dormir & \\
\hline $\begin{array}{l}\text { Q24 - tenho bastante tempo depois do } \\
\text { trabalho para resolver assuntos pessoais }\end{array}$ & \\
\hline $\begin{array}{l}\text { Q25 - tenho tempo suficiente para minha } \\
\text { família }\end{array}$ & \\
\hline $\begin{array}{l}\text { Q26 - tenho tempo suficiente para meus } \\
\text { amigos }\end{array}$ & \\
\hline Q27 - sinto muitc & \\
\hline
\end{tabular}

Fonte: Altoé (2014).

Além das questões relacionadas ao Work-Life Balance e a gestão de tempo (segundo bloco do questionário desta pesquisa) foram solicitadas informações pessoais dos 
respondentes (no Bloco 1). Esse bloco de perguntas foi composto por nove questões relativas a idade, gênero, estado civil, se tem filhos (quantidade), nível e área de formação, setor e tempo de trabalho na empresa estudada.

A análise dos dados foi feita, inicialmente, de forma descritiva, e posteriormente com o auxílio de estatística. Como a amostra estudada foi pequena (menos de 50 respondentes), para checar a normalidade dos dados optou-se pelo teste de normalidade de Shapiro-Wilk. O teste apontou não-normalidade para todas as variáveis analisadas. Com isso, a análise dos dados foi desenvolvida com base em estatística nãoparamétrica, especificamente, por meio do Teste $U$ de Mann-Whitney, que busca comparar a mediana de dois grupos, no caso desta pesquisa: funcionários com horários flexibilizados versus os funcionários que não dispõem deste benefício. Os achados da pesquisa estão apresentados na seção 4 .

\section{Apresentação e discussão dos resultados}

\section{PERFIL DOS RESPONDENTES}

0 resumo das informações sobre o perfil dos respondentes consta na Tabela 1 . No que tange aos 38 respondentes da pesquisa, aproximadamente $70 \%$ têm menos de trinta anos de idade. Dentre esses, $60 \%$ pertence ao grupo $\mathrm{A}$, e $40 \%$ ao $\mathrm{B}$, indicando que os colaboradores são predominantemente jovens e que se encontram relativamente distribuídos entre os setores enquadrados nos dois grupos. Dos 10 colaboradores com mais de trinta anos, somente uma possui mais de quarenta.

Tabela 1 Perfil dos respondentes por grupo

\begin{tabular}{|c|c|c|}
\hline & Grupo A & Grupo B \\
\hline \multicolumn{3}{|l|}{ Gênero } \\
\hline Masculino & 12 & 13 \\
\hline Feminino & 8 & 5 \\
\hline \multicolumn{3}{|l|}{ Idade } \\
\hline$<30$ anos & 17 & 11 \\
\hline 30 anos $<$ & 3 & 7 \\
\hline \multicolumn{3}{|c|}{ Estado Civil } \\
\hline Solteiro & 13 & 9 \\
\hline Casado & 7 & 9 \\
\hline \multicolumn{3}{|l|}{ Filhos } \\
\hline Sim & 4 & 3 \\
\hline Não & 16 & 15 \\
\hline
\end{tabular}

Fonte: Dados da pesquisa.

Do total de respondentes, $65 \%$ são do gênero masculino e 35\% do gênero feminino, ou seja, 25 e 13 pessoas, respectivamente, igualmente distribuídas entre os dois grupos, aproximando-se da análise do estado civil, a qual indica que cerca de $60 \%$ dos respondentes são solteiros ( 22 pessoas), enquanto os $40 \%$ restantes são casados ou estão em união estável (16 pessoas). Nota- se, que os dois grupos do estado civil também se distribuem equilibradamente entre os grupos $A$ e $B$, em outras palavras, os solteiros e casados se fazem presentes tanto nos setores com horários totalmente flexíveis como nos setores com horários não flexibilizados. Somente 4 pessoas do Grupo A e 2 do grupo B afirmaram ter filhos. Um dos respondentes informou ter mais do que um (dois filhos) - funcionário do grupo B.

Quanto ao nível de escolaridade, aproximadamente $30 \%$ dos participantes estão cursando o ensino superior, $55 \%$ já o completaram e $15 \%$ possui pós-graduação em nível de especialização ou MBA. Em função da análise da distribuição dessas variáveis entre os grupos $A$ e $B$, observa-se mais uma vez um equilíbrio, sendo assim, a organização conta com pessoas de diferentes níveis de escolaridade nos setores, com flexibilização, ou não, de horários.

Das quatorze formações identificadas, três estão distribuídas entre os dois grupos $(A$ e $B)$ e, juntas, representam aproximadamente $55 \%$ do total dos cursos de formação da amostra. São eles: Administração (30\%), Sistemas de Informação (15\%) e Gestão de Recursos Humanos (10\%). A formações em: Ciência da Computação, Comunicação Social, Engenharia de Computação, Jornalismo, Psicologia e Marketing são encontradas somente no grupo com horários totalmente flexíveis, ao contrário das formações em: Direito, Relações internacionais, Técnico em manutenção de Aeronaves, Tecnologia em Comércio Exterior, Engenharia Elétrica e Publicidade e Propaganda, inseridas no grupo com horários não flexibilizados.

O tempo de trabalho na Involves, dos respondentes, em meses, está apresentado na Figura 1.

Figura 1 Tempo de trabalho na Involves (em meses)

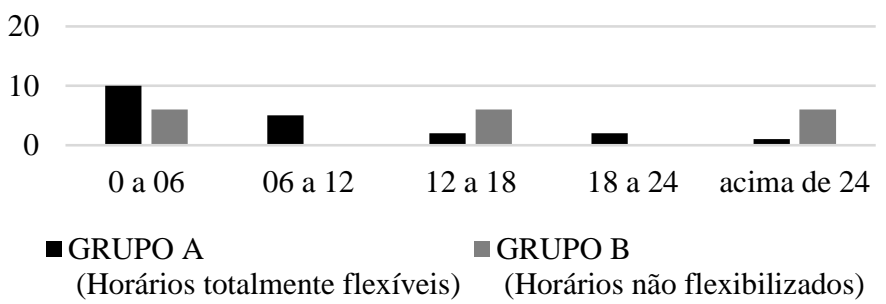

Fonte: Dados da pesquisa

De acordo com a diretoria da empresa, ao longo da evolução da organização, são observados baixos índices de turnovers dos funcionários. Assim, pode-se afirmar com base na Figura 1. Que a contratação de trabalhadores dos setores com horários flexíveis, vem apresentando uma expansão nos últimos dois anos, enquanto as contratações para os setores com horários não flexibilizados, aparentemente, ocorreram com um maior espaço de tempo e em quantidade constante de pessoal.

As características dos funcionários, e os grupos A e B, até aqui apresentados, são analisados na sessão seguinte, no que tange a gestão de tempo e equilíbrio entre vida pessoal e profissional.

\section{PERCEPÇÃO DA GESTÃO DE TEMPO E WORK-LIFE BALANCE PELOS FUNCIONÁRIOS DA INVOLVES}

No que tange a codificação das questões relacionadas a gestão de tempo, disponível na Tabela 2, observa-se que há um 
alto nível de satisfação dos funcionários, principalmente no que se refere ao tempo disponível para dormir, para ficar com a família e ao ânimo dos funcionários após o trabalho.

A codificação das respostas relacionadas ao WorkLife Balance está apresentada na Tabela 3. De acordo com os dados, algumas das questões se destacam por terem um número de respostas concentradas nas opções "4" (concorda parcialmente) e "5" (concorda totalmente). É o caso das questões: Q3, Q7, Q8, Q10, Q11, Q14, Q15, Q19 e Q22, ou seja, são as afirmações com que os respondentes mais concordaram e concentram, individualmente, aproximadamente de $60 \%$ a até $90 \%$ do total das respostas dos participantes.

Tabela 2 Codificação dos fatores relacionados a gestão de tempo

\begin{tabular}{l|c|c|c|c|c}
\hline \multicolumn{1}{c|}{ Questões } & $\mathbf{1}$ & $\mathbf{2}$ & $\mathbf{3}$ & $\mathbf{4}$ & $\mathbf{5}$ \\
\hline $\begin{array}{l}\text { Q23 - tenho tempo suficiente para } \\
\text { dormir }\end{array}$ & 2 & 4 & 3 & 10 & 19 \\
\hline $\begin{array}{l}\text { Q24 - tenho bastante tempo } \\
\text { depois do trabalho para resolver } \\
\text { assuntos pessoais }\end{array}$ & 1 & 8 & 7 & 13 & 9 \\
\hline $\begin{array}{l}\text { Q25 - tenho tempo suficiente para } \\
\text { minha família }\end{array}$ & 0 & 3 & 4 & 20 & 11 \\
\hline $\begin{array}{l}\text { Q26 - tenho tempo suficiente para } \\
\text { meus amigos }\end{array}$ & 1 & 6 & 7 & 15 & 9 \\
\hline $\begin{array}{l}\text { Q27 - me sinto muito animado } \\
\text { depois do trabalho }\end{array}$ & 0 & 2 & 5 & 12 & 19 \\
\hline
\end{tabular}

Fonte: Dados da pesquisa.

Dessas nove questões, quatro focam especialmente no elemento da compreensão e do apoio dos supervisores e colegas no trabalho (Q8, Q10, Q11, Q14), portanto, indica-se um auto grau de compreensibilidade com as questões relacionadas ao Work-Life Balance entre as equipes. A questão que contraria as anteriores neste sentido é a Q16, por relacionar-se ao apoio dos colegas para a redução de carga horária do respondente para dedicar-se mais à vida pessoal. Neste caso os resultados indicam que $50 \%$ dos entrevistados discordam totalmente dessa afirmação, enquanto quase 35\% não concorda nem discorda.

Tabela 3 Codificação dos fatores relacionados ao Work-Life Balance

\begin{tabular}{l|l|l|l|l|c}
\hline \multicolumn{1}{c|}{ Questões } & $\mathbf{1}$ & $\mathbf{2}$ & $\mathbf{3}$ & $\mathbf{4}$ & $\mathbf{5}$ \\
\hline $\begin{array}{l}\text { Q3 - Tenho tempo para a realização de } \\
\text { interesses e aspirações pessoais. }\end{array}$ & 0 & $\mathbf{1}$ & $\mathbf{9}$ & 14 & 14 \\
\hline
\end{tabular}

Q4 - Optaria por redução da carga horária

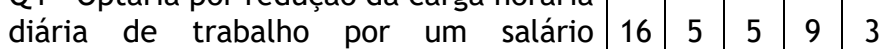
proporcional.

Q6 - Desistiria de assumir um cargo elevado no trabalho, para me dedicar mais a família e vida pessoal.

Q7 - Meu tempo livre (fora do trabalho) pode ser utilizado para situações imprevisíveis.

Q8 - Meus colegas de trabalho compreendem quando abordo questões

\begin{tabular}{l|l|l|l|l|l}
\hline $\begin{array}{l}\text { pessoais ou familiares que afetam o } \\
\text { trabalho. }\end{array}$ & & & & \\
\hline $\begin{array}{l}\text { Q10 - Aceito realizar horas extras pois } \\
\text { estou comprometido com o trabalho. }\end{array}$ & 0 & 1 & 2 & 7 & 28 \\
\hline $\begin{array}{l}\text { Q11 - Meu supervisor imediato } \\
\text { compreende quando comento questões } \\
\text { pessoais ou familiares que afetam o }\end{array}$ & 0 & 1 & 2 & 3 & 32 \\
trabalho. & & & & & \\
\hline $\begin{array}{l}\text { Q12 - Levo trabalho para finalizar em } \\
\text { casa. }\end{array}$ & 15 & 11 & 5 & 5 & 2 \\
\hline $\begin{array}{l}\text { Q13 - Aceito realizar horas extras pois é } \\
\text { essencial para a progressão de minha } \\
\text { carreira. }\end{array}$ & 6 & 7 & 8 & 11 & 6 \\
\hline $\begin{array}{l}\text { Q14 - Consigo programar a melhor data } \\
\text { para tirar férias e tenho o apoio de meus } \\
\text { colegas de trabalho. }\end{array}$ & 0 & 1 & 4 & 8 & 25 \\
\hline $\begin{array}{l}\text { Q15 - Consigo conciliar meu trabalho com } \\
\text { minha vida pessoal e familiar, em função } \\
\text { da flexibilidade de horários que o trabalho } \\
\text { proporciona. }\end{array}$ & 1 & 1 & 2 & 10 & 24 \\
\hline $\begin{array}{l}\text { Q16 - Penso em reduzir minha jornada de } \\
\text { trabalho para me dedicar mais tempo as } \\
\text { minhas atividades pessoais ou familiares e } \\
\text { tenho o apoio de meus colegas de } \\
\text { trabalho. }\end{array}$ & 13 & 6 & 13 & 5 & 1 \\
\hline $\begin{array}{l}\text { Q19 - Consigo cumprir com minhas } \\
\text { obrigações no trabalho dentro da carga } \\
\text { horária contratada. }\end{array}$ & 1 & 1 & 2 & 10 & 24 \\
\hline $\begin{array}{l}\text { Q22 - Aceito trabalhar pelo menos 10 } \\
\text { horas por dia para mantero meu trabalho. }\end{array}$ & 1 & 7 & 3 & 13 & 11 \\
\hline Fonte: Dados da pesqusa. & & & & & \\
\hline
\end{tabular}

Fonte: Dados da pesquisa.

As afirmações nas questões Q3 e Q7 focam no equilíbrio entre tempo livre e vida pessoal, enquanto nas Q19 e Q22 focam no equilíbrio entre tempo livre e vida profissional, sendo assim, há indícios de que não haveria conflito entre os papéis em casa e no trabalho. A Involves demonstrou-se uma empresa com funcionários relativamente jovens, dos quais grande parte são solteiros e/ou não possuem filhos. Esse fator pode ter contribuído no resultado das respostas das questões Q3, Q7, Q19 e Q22, uma vez que, aparentemente, nesses casos seria mais fácil equilibrar as demandas da vida familiar. A afirmação Q15, por outro lado, tem um enfoque na conciliação entre o conflito dos papéis de trabalho em função da flexibilidade de horários, confirmando os resultados encontrados nas quatro últimas questões comentadas.

Das afirmações listadas, as questões Q4, Q12, além da Q16, já mencionada, se destacam por terem um número de respostas concentradas nas opções " 1 ” (discorda totalmente) e "2" (discorda parcialmente), ou seja, são as afirmações com que os respondentes menos concordaram e concentram, individualmente, aproximadamente de $50 \%$ a até $70 \%$ do total das respostas. As respostas da questão Q4 indicam que mais da metade dos respondentes não optaria por uma carga horária de trabalho menor com a condição de um menor salário. A questão Q12, de certa forma, complementa os achados da questão Q22 (65\% aceitam trabalhar mais para manter o trabalho), por informar que quase $70 \%$ dos colaboradores envolvidos no questionário não leva trabalho para finalizar em casa.

Duas das afirmações, questões Q6 e Q13, geraram respostas bem distribuídas, o que permite inferir que os funcionários da empresa priorizam de forma distinta questões 
relacionadas a maior tempo para a vida pessoal e ascensão profissional.

De forma geral, diante dos dados apresentados nas Tabelas 2 e 3, pode-se afirmar que os funcionários percebem que têm uma gestão adequada do tempo e equilíbrio entre vida pessoal e profissional. Com a finalidade de alcançar o objetivo, bem como testar as quatro hipóteses da presenta pesquisa, na seção seguinte, os dados relacionados as características dos funcionários e a flexibilização do horário de trabalho são analisadas conjuntamente com as informações de percepção da gestão de tempo e do Work-Life Balance.

\section{REFLEXO DAS CARACTERÍSTICAS DOS FUNCIONÁRIOS E FLEXIBILIDADE DO HORÁRIO DE TRABALHO NA PERCEPÇÃO DA GESTÃO DE TEMPO E WORK-LIFE BALANCE}

Considerando-se a natureza das variáveis e a confirmação da não normalidade dos dados por meio do teste de Shapiro-Wilk, a análise dos dados foi desenvolvida com base em estatística não-paramétrica. Embora seja recorrente na literatura o tratamento de escalas intervalares (como a Likert) da mesma forma que escalas de razão, na presente pesquisa optou-se por seguir os princípios da teoria da medida, respeitando a legitimidade no uso de números na descrição dos fenômenos naturais (Pasquali, 2003). Dessa forma o Teste $U$ de Mann-Whitney foi aplicado a cada uma das variáveis ( 5 referentes a gestão de tempo e 14 referentes ao Work-Life Balance), ao invés da junção das variáveis por meio de soma ou médias.

No que se refere a primeira hipótese $(\mathrm{H} 1)$ desta pesquisa, há diferença na percepção da gestão de tempo entre indivíduos com características distintas, foi possível identificar que tanto a área de formação $(p=0,008)$, quanto a idade dos funcionários $(p=0,045)$ leva a uma percepção diferente da adequabilidade da gestão de tempo. Os indivíduos com formação na área de tecnologia e com menos de trinta anos apontaram ter menos tempo para dormir do que os demais (Q23). Como o fato de não ter concluído a graduação não foi significativamente relevante, esse fator não pode ser apontado como o motivador para essa diferença. A hipótese que pode ser proposta para justificar a diferença encontrada, com relação a essas características é que os indivíduos mais jovens, com formação em áreas relacionadas à tecnologia da informação podem estar dedicando seu tempo para atividades extras, sejam relacionadas a vida profissional ou lazer.

A partir da análise da segunda hipótese $(\mathrm{H} 2)$, de que há diferença na percepção de Work-Life Balance ente indivíduos com características distintas, os indivíduos com formação na área de tecnologia da informação $(p=0,008)$ aparecem novamente com uma posição diferente dos demais, especificamente no que se refere a possibilidade de reduzir a carga horária de trabalho por um salário proporcional, reforçando ainda mais a ideia de que esses profissionais podem estar desenvolvendo atividades extras, ou seja, trabalhos além dos desenvolvidos para a Involves.

Diante dos dados apresentados, tanto $\mathrm{H} 1$, quanto $\mathrm{H} 2$ são parcialmente sustentadas, corroborando com Chandra (2012) no que diz respeito a influência de características dos indivíduos influenciar na forma como gerenciam o tempo e percebem o equilíbrio entre vida pessoal e profissional. A sustentação é parcial uma vez que as hipóteses foram testadas diante das características idade, gênero, estado civil, filhos, nível e área de formação e tempo de trabalho na empresa estudada e foram estatisticamente significativas, para formação e idade na análise relacionada a gestão de tempo e apenas formação no caso do Work-Life Balance.

No que tange a terceira $(\mathrm{H} 3)$ e quarta $(\mathrm{H} 4)$ hipóteses, que se referem a diferença na percepção da gestão de tempo e Work-Life Balance, respectivamente, entre indivíduos com carga horária de trabalho flexibilizada (Grupo A) e não flexibilizada (Grupo B) não foram encontradas diferenças. Tal achado aponta para um mesmo nível de percepção da adequabilidade da gestão de tempo e Work-Life Balance entre os funcionários que trabalham com horários flexíveis e com horários pré-fixados. 0 que indica que a rotina proporcionada pela empresa permite que os funcionários, mesmo os do segundo grupo, tenham uma rotina agradável e sinta-se satisfeito com a forma como o seu tempo está organizado e com a forma como sua rotina está dividida entre as atividades pessoais e laborais. Refutam-se, assim, as hipóteses H3 e H4, propostas.

Um resumo do resultado das hipóteses propostas é apresentado no Quadro 2.

Quadro 2 - Resultado das hipóteses propostas

\begin{tabular}{|c|c|}
\hline Hipóteses & Decisão \\
\hline $\begin{array}{l}\text { H1: Há diferença na percepção da } \\
\text { gestão de tempo entre indivíduos com } \\
\text { características distintas. }\end{array}$ & Parcialmente aceita. \\
\hline $\begin{array}{l}\text { H2: Há diferença na percepção de } \\
\text { Work-Life Balance ente indivíduos com } \\
\text { características distintas. }\end{array}$ & Parcialmente aceita. \\
\hline $\begin{array}{l}\text { H3: Há diferença na percepção da } \\
\text { gestão de tempo entre indivíduos com } \\
\text { carga horária de trabalho flexibilizada } \\
\text { e não flexibilizada. }\end{array}$ & Rejeitada. \\
\hline $\begin{array}{l}\text { H4: Há diferença na percepção de } \\
\text { Work-Life Balance entre indivíduos } \\
\text { com carga horária de trabalho } \\
\text { flexibilizada e não flexibilizada. }\end{array}$ & Rejeitada. \\
\hline
\end{tabular}

Fonte: Dados da pesquisa

A próxima seção apresenta as conclusões e reflexões à luz dos aspectos investigados neste estudo.

\section{Conclusões}

0 presente estudo teve como objetivo verificar se as características dos funcionários e a flexibilidade da jornada de trabalho proposta por uma empresa de tecnologia da Grande Florianópolis refletem na percepção de gestão adequada de tempo e, respectivamente, no equilíbrio entre vida pessoal e 
laboral (Work-Life Balance) dos colaboradores. A pesquisa classifica-se como descritiva, sendo os dados coletados a partir da aplicação de um questionário aos funcionários de uma empresa de tecnologia da Grande Florianópolis, com posterior análise estatística.

Cerca de $40 \%$ dos funcionários da empresa participaram do estudo (38 respondentes). Inicialmente, o perfil dos respondentes foi discutido com base em dois grupos: os funcionários que trabalham com horários flexibilizados (Grupo A) e aqueles que trabalham com horários pré-fixados (Grupo B). Posteriormente, foram analisadas as respostas dos funcionários no que tange a percepção da gestão de tempo e Work-Life Balance. A análise descritiva permite inferir que os funcionários compreendem a gestão de tempo como adequada e que há equilíbrio entre a rotina pessoal e laboral.

No que se refere ao reflexo das características pessoais e da flexibilização da carga horária de trabalho nessa compreensão, os resultados estatísticos permitem inferir que há uma influência parcial das características dos funcionários, no que se refere a formação e idade no tempo destinado ao sono - item que compõem a gestão de tempo -, e da formação, também, no que diz respeito a aceitar reduzir a carga horária, com redução proporcional dos salários - item relacionado ao Work-Life Balance -, indicando que profissionais da área de tecnologia da informação e mais jovens, provavelmente desenvolvem atividades laborais além das prestadas para a Involves.

Não foi encontrada diferença estatisticamente significativa, entre os funcionários que possuem horários de trabalho flexibilizados e pré-fixados, na gestão do tempo e no equilíbrio entre vida pessoal e laboral dos trabalhadores da organização. Sustenta-se que esse resultado pode ter atribuído ao ambiente de trabalho oferecido pela empresa a todos os funcionários, que mesmo não tendo uma flexibilização de horários, desenvolvem suas atividades em um contexto mais descontraído se comparado a organizações tradicionais, com atividades de lazer propiciados aos funcionários por parte da empresa, entre outros, que tornam a local de trabalho mais atrativo e evita um alto índice de turnover.

Por meio da revisão da literatura, foi possível notar que as temáticas de gestão de tempo e Work-Life Balance têm sido pouco abordadas no Brasil, até o momento, além de serem relativamente recentes, também, em pesquisas internacionais. No entanto, é considerada relevante a medida em que se percebe uma preocupação tanto dos empregadores, com um olhar voltado para a produtividade e redução de custos dentro da organização, quanto dos empregados, na busca por um equilíbrio entre os papéis e as demandas de trabalho na vida pessoal e laboral.

Com o propósito de ampliar os estudos acerca da temática do Work-Life Balance e da flexibilização do trabalho, recomenda-se, para estudos futuros, a comparação de duas empresas distintas, uma com um perfil flexibilizado e a outra com o perfil não flexibilizado, afim de traçar um resultado mais assertivo a respeito da relação entre os dois temas. Recomendase ainda, envolver uma população com mais pessoas casadas, em união estável e/ou com filhos, por trazer peso nas demandas decorrentes da vida familiar, na busca pela maior compreensão do conflito entre essas demandas e as decorrentes do trabalho.

\section{Referências}

Altoé, S. M. L. (2014). Fatores explicativos do Work-Life balance de contadores à luz da psicologia positiva. 2014. 142 f.. Mestrado em Contabilidade - Universidade Federal do Paraná, Curitiba.

Andrade, M. C. P. (2011). Work-Life Balance: Condições de trabalho facilitadoras da integração do papel profissional e familiar. Exedra: Revista Científica, (1), 41-54.

Baltes, B. B., Clark, M. A., \& Chakrabarti, M. (2010). 16 WorkLife Balance: The Roles of Work-Family Conflict and WorkFamily Facilitation.

Beauregard, T. A., \& Henry, L. C. (2009). Making the link between work-life balance practices and organizational performance. Human resource management review, 19(1), 922.

Chandra, V. (2012). Work-life balance: Eastern and western perspectives. The International Journal of Human Resource Management, 23(5), 1040-1056.

Covey, S. R. (2005). Os sete hábitos das pessoas altamente eficazes. São Paulo: Best.

Darcy, C., McCarthy, A., Hill, J., \& Grady, G. (2012). Work-life balance: One size fits all? An exploratory analysis of the differential effects of career stage. European Management Journal, 30(2), 111-120.

Isaacs, D. (2016). Work-life balance, Journal of Pediatrics and Child Health, v. 52, 2016.

Lima, M. D. C. F., \& Jesus, S. B. (2011). Administração do tempo: um estudo sobre a gestão eficaz do tempo como ferramenta para o aumento da produtividade e work life balance. Revista de Gestão e Secretariado, 2(2), 121-144.

Moen, P., Kelly, E. L., Tranby, E., \& Huang, Q. (2011). Changing work, changing health: can real work-time flexibility promote health behaviors and well-being?. Journal of Health and Social Behavior, 52(4), 404-429.

Moen, P., Fan, W., \& Kelly, E. L. (2013). Team-level flexibility, work-home spillover, and health behavior. Social Science \& Medicine, 84, 69-79.

Moen, P., Kelly, E. L., \& Hill, R. (2011). Does enhancing worktime control and flexibility reduce turnover? A naturally occurring experiment. Social problems, 58(1), 69-98.

Paludo, S. D. S., \& Koller, S. H. (2007). Psicologia Positiva: uma nova abordagem para antigas questões. Paidéia: cadernos de educação da Faculdade de Filosofia, Ciências e Letras de Ribeirão Preto. Ribeirão Preto, SP. Vol. 17, n. 36 (2007), p. 920.

Pasquali, L. (2017). Psicometria: teoria dos testes na psicologia e na educação. Editora Vozes Limitada.

Perlow, L. A., \& Kelly, E. L. (2014). Toward a model of work redesign for better work and better life. Work and Occupations, 41(1), 111-134. 
Robortella, L. C. A. (1994). O moderno direito do trabalho: flexibilização, terceirização; novas tecnologias, contratos atípicos; participação na empresa. Ed. LTr.

Saltzstein, A. L., Ting, Y., \& Saltzstein, G. H. (2001). Work-family balance and job satisfaction: The impact of family-friendly policies on attitudes of federal government employees. Public administration review, 61(4), 452-467.

Sutton, K. L., \& Noe, R. A. (2005). Family-friendly programs and work-life integration: more myth than magic?. na.

Tasca, C. F. F. B., \& Bezerra, C. S. (2017). A indisponibilidade dos direitos do trabalhador em face da flexibilização da legislação trabalhista brasileira. Revista Âmbito Jurídico, (159).

Vignoli, V. D. A. (2010). Flexibilização da jornada de trabalho: importância e limitações (Doctoral dissertation, Universidade de São Paulo).

Vogelmann, E. M. (2012). Flexibilização da carga horária como forma de motivação organizacional.

Wong, S. C. K., \& Ko, A. (2009). Exploratory study of understanding hotel employees' perception on work-life balance issues. International Journal of Hospitality Management, 28(2), 195-203.

Wu, L., Rusyidi, B., Claiborne, N., \& McCarthy, M. L. (2013). Relationships between work-life balance and job-related factors among child welfare workers. Children and Youth Services Review, 35(9), 1447-1454. 